\title{
KUWAITIMYCIN, EFFECT ON SYNTHESIS OF LIPIDS IN BACILLUS SUBTILIS CELLS
}

\author{
Ibrahim R. Shimi, Safwat Shoukry and Zeinab Zaki \\ Faculty of Science, Ain Shams University, Biochemistry Department, Cairo, A.R.E.
}

(Received for publication May 2, 1977)

\begin{abstract}
The effects exerted by kuwaitimycin on synthesis of lipids as well as some metabolic activities of Bacillus subtilis were studied. The antibiotic not only arrested the incorporation of ${ }^{14} \mathrm{C}$-acetate into the microbial lipids but also altered the fatty acids pattern, contents of i-C 15 , a-C 15, i-C 17 and a-C 17 were markedly reduced, concomitant with an increase in the contents of i-C 14 and n-C 14. Moreover, the rates of synthesis of phospholipids were decreased by the drug, especially that of phosphatidyl ethanolamine.
\end{abstract}

Kuwaitimycin is a peptolide antibiotic containing several amino acids and isohexadeca- 3,6 dienoic acid as the fatty acid moiety ${ }^{1)}$ of the molecule.

The effect of the antibiotic on transport of alkali earth metal ions through mitochondrial membrane was demonstrated by SHIMI ${ }^{2)}$.

During the present work the probable effects exerted by kuwaitimycin on synthesis of lipids and some other metabolic activities of $B$. subtilis were explored in order to locate its primary site of action on the microbial test organism.

\section{Materials and Methods}

Kuwaitimycin was prepared and purified as described by SHIMI $e t$ al ${ }^{11}$.

Bacillus subtilis icc was grown in nutrient broth having the following composition $(\mathrm{g} / 100 \mathrm{ml})$ : peptone, $0.5 ; \mathrm{NaCl}, 0.5$, meat extract, 0.15 and yeast extract 0.15 . Cultures were shaken at $220 \mathrm{rpm}$ at $35^{\circ} \mathrm{C}$ and the bacterial cells were then harvested at $15,000 \times g$ during the middle logarithmic phase of growth. The harvest was diluted with sterile medium to produce a bacterial suspension of O.D. 0.4 at $660 \mathrm{~nm}$. This preparation was used throughout the following experiments.

The effect of kuwaitimycin on the biosynthesis of macromolecules was carried out as described before $^{32}$.

\section{Effect of Kuwaitimycin on Lipid Synthesis of B. subtilis}

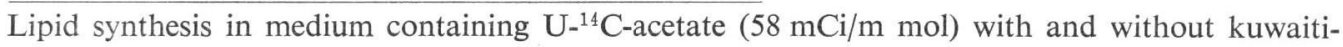
mycin was investigated. Details of experimental conditions were as follows: $5 \mathrm{ml}$ samples of the cultures were withdrawn at appropriate incubation periods and the bacterial cells were harvested by centrifugation. The lipid content of the harvested cells was extracted as described by BLIGH \& DYER ${ }^{4}$. A portion of each lipid extract was used for radioactivity measurements using a liquid scintillation spectrometer Nuclear Chicago Mark II in a toluene-based PPO-POPOP system. The rest of the lipid extract was used for identification of phospholipids by TLC using chloroform - methanol - acetic acid $(65: 25: 10, \mathrm{v} / \mathrm{v})$ as developing solvent. Location of spots on developed chromatograms was carried out by comparison with authentic samples of phospholipids. The radiochemicals were purchased from the Radiochemical Centre, Amersham, Bucks, U.K.

Effect of Kuwaitimycin on Fatty Acid Synthesis in B. subtilis Cells

Equal portions of the bacterial preparation were separately diluted with equal volumes of the fresh warm sterile medium containing different concentrations of kuwaitimycin and then incubated for different periods at $37^{\circ} \mathrm{C}$. The bacterial cells were harvested by centrifugation and their lipid con- 
tents were extracted ${ }^{4}$, methylated $^{5)}$, and analysed by GLC using a 20\% PEGA column. Results and experimental details are given in Table 1 and the legend.

\section{Results and Discussion}

The effect of kuwaitimycin on B. subtilis growth is given in Fig. 1. Kuwaitimycin did not exert significant effects on the synthesis of labeled macromolecules at early incubation periods.

Kuwaitimycin partially arrested the utilization of ${ }^{14} \mathrm{C}$-acetate by the organism (Fig. 2). The rate

Fig. 1. Effect of kuwaitimycin on the growth of

B. subtilis

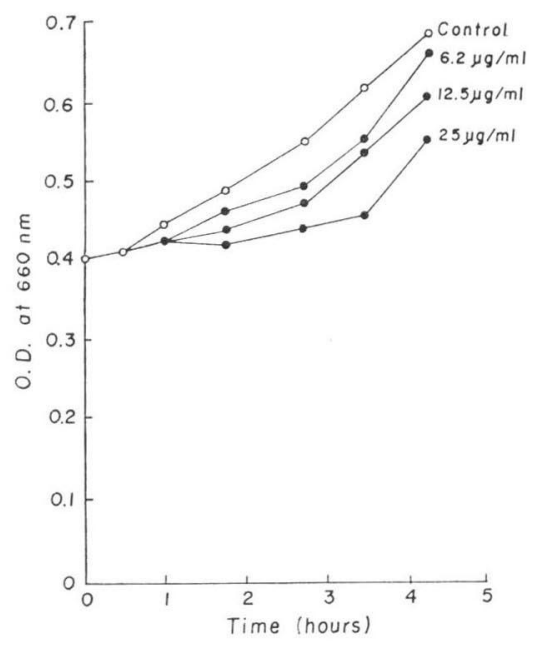

Fig. 2. Effect of kuwaitimycin on the incorporation of $\mathrm{U}^{-14} \mathrm{C}$-acetate into $B$. subtilis lipids

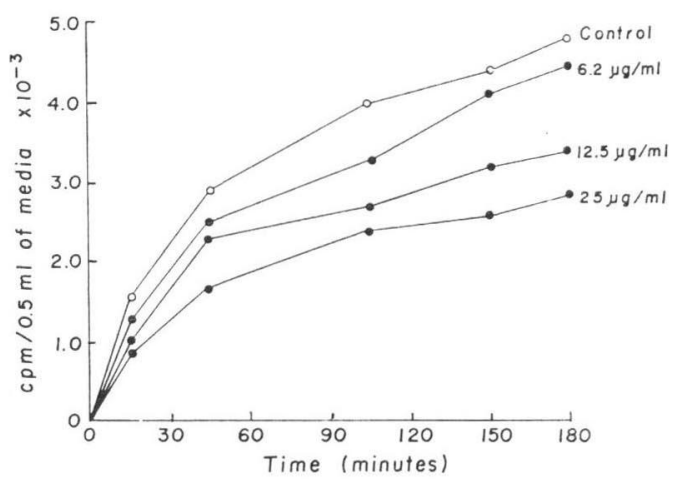

Fig. 3. Effect of kuwaitimycin on the phospholipid synthesis in B. subtilis cells

The identified phospholipid spots were scraped off from the TLC plates and their radioactivity was counted in polyethylene vials using the scintillation cocktail given in the text containing $4 \%(\mathrm{w} / \mathrm{v})$ Cab-o-Sil.
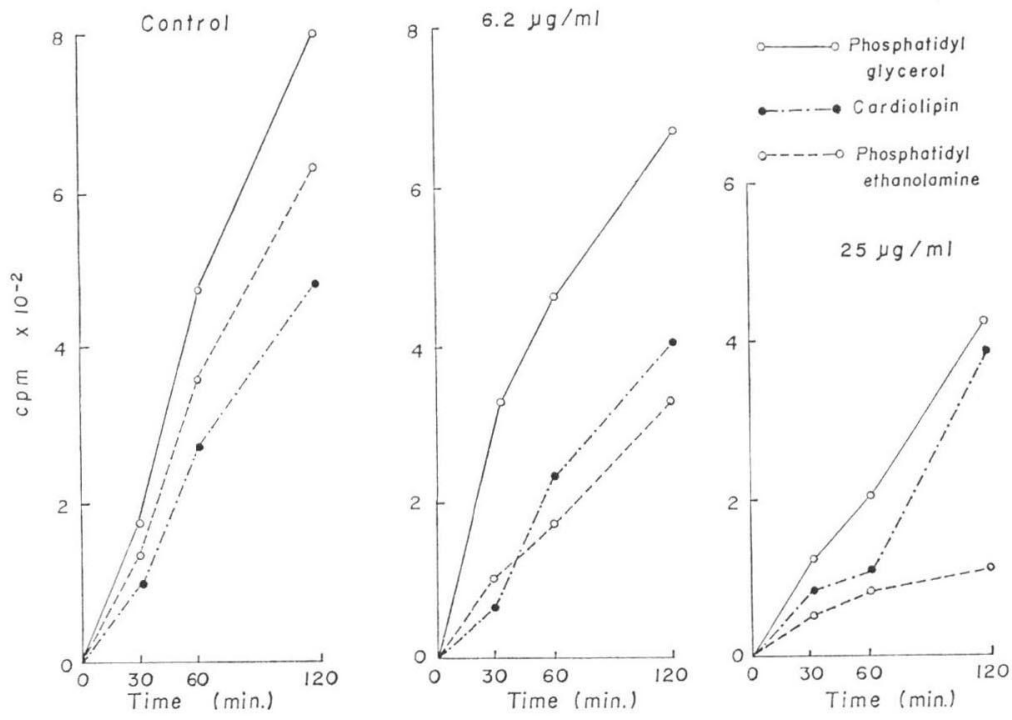
of synthesis of phosphatidyl ethanolamine was markedly reduced at the MIC level of the antibiotic when compared with the control data, whereas the synthesis of cardiolipin and phosphatidyl glycerol were less markedly affected (Fig. 3). Similar results were also reported for phenethyl alcohol $^{6)}$, polyketoacidomycin ${ }^{7)}$ and polymyxins ${ }^{8)}$. The decrease in the rates of synthesis of phospholipids became more pronounced the higher the concentration of the antibiotic applied (Fig. 3). Moreover, the relative contents of the fatty acids of C-15 and C-17 were reduced while the contents of i-C 14 and n-C 14 were increased (Table 1). RINGRASE \& HigGins ${ }^{9)}$ reported similar findings in fatty acids pattern of $E$. coli treated cells.

Release of $\mathrm{Na}^{+}$and $\mathrm{K}^{+}$ions from inside the bacterial cells (Table 2) was augmented by kuwaiti-

Table 1. Effect of kuwaitimycin on the fatty acid pattern of B. subtilis cells

\begin{tabular}{|c|c|c|c|c|c|c|c|c|c|c|c|c|}
\hline \multirow{4}{*}{ Fatty acids* } & \multicolumn{12}{|c|}{ Concentration of fatty acids ( $\mu \mathrm{g} / \mathrm{mg}$ cell dry weight) } \\
\hline & \multicolumn{3}{|c|}{15 minutes } & \multicolumn{3}{|c|}{40 minutes } & \multicolumn{3}{|c|}{60 minutes } & \multicolumn{3}{|c|}{120 minutes } \\
\hline & \multicolumn{12}{|c|}{ Concentration of kuwaitimycin $(\mu \mathrm{g} / \mathrm{ml})$} \\
\hline & 0.00 & 6.2 & 12.5 & 0.00 & 6.2 & 12.5 & 0.00 & 6.2 & 12.5 & 0.00 & 6.2 & 12.5 \\
\hline $\mathrm{i}-14$ & 0.30 & 0.3 & 0.55 & 0.33 & 0.35 & 0.58 & 0.4 & 0.32 & 0.6 & 0.59 & 1.04 & 0.71 \\
\hline n-14 & 0.10 & 0.11 & 0.32 & 0.13 & 0.15 & 0.50 & 0.16 & 0.12 & 0.5 & 0.35 & 1.04 & 0.44 \\
\hline $\mathrm{i}-15$ & 9.11 & 8.53 & 8.01 & 9.00 & 8.45 & 7.99 & 9.88 & 8.61 & 8.23 & 10.9 & 8.85 & 8.42 \\
\hline$a-15$ & 8.83 & 8.32 & 8.10 & 8.98 & 8.13 & 7.50 & 9.36 & 8.45 & 8.4 & 10.01 & 8.36 & 8.33 \\
\hline $\mathrm{i}-16$ & 0.87 & 0.62 & 0.75 & 1.21 & 1.36 & 0.93 & 1.44 & 1.97 & 1.28 & 1.51 & 2.04 & 1.42 \\
\hline$n-16$ & 2.91 & 3.15 & 2.86 & 3.02 & 3.23 & 3.30 & 3.12 & 3.15 & 3.90 & 3.63 & 3.10 & 3.86 \\
\hline $\mathrm{i}-17$ & 4.01 & 3.55 & 3.13 & 4.40 & 3.50 & 3.13 & 4.48 & 3.63 & 3.40 & 5.01 & 3.84 & 3.77 \\
\hline$a-17$ & 2.00 & 1.52 & 1.31 & 2.40 & 1.56 & 1.38 & 2.40 & 2.00 & 1.82 & 2.80 & 2.01 & 1.83 \\
\hline
\end{tabular}

The fatty acid methyl esters are subjected to gas-liquid chromatography on $20 \%$ PEGA column at $185^{\circ} \mathrm{C}$ using $\mathrm{N}_{2}$ as carrier gas ( $40 \mathrm{ml} /$ minute). Analysis was carried out on PYE UNICAM GCV.

* n-14 \& n-16=normal fatty acids of $14 \& 16$ carbon atoms respectively. $\mathrm{i}-14, \mathrm{i}-15, \mathrm{i}-16 \& \mathrm{i}-17=$ iso fatty acids of $14,15,16 \& 17$ carbon atoms respectively. a-15 \& a-17 $=$ anteiso fatty acids of $15 \& 17$ carbon atoms respectively.

Table 2. Effect of kuwaitimycin on the intracellular concentration of $\mathrm{Na}$ and $\mathrm{K}$ ions

\begin{tabular}{|c|c|c|c|c|c|c|}
\hline & \multicolumn{6}{|c|}{ Concentration of kuwaitimycin $(\mu \mathrm{g} / \mathrm{ml})$} \\
\hline & \multicolumn{2}{|c|}{0.00} & \multicolumn{2}{|c|}{6.2} & \multicolumn{2}{|c|}{12.5} \\
\hline & \multicolumn{6}{|c|}{ Cations concentration* ( $\mu \mathrm{g} / \mathrm{mg}$ cell dry weight) } \\
\hline & $\mathrm{Na}^{+}$ & $\mathrm{K}^{+}$ & $\mathrm{Na}^{+}$ & $\mathrm{K}^{+}$ & $\mathrm{Na}^{+}$ & $\mathbf{K}^{+}$ \\
\hline $15 \mathrm{~min}$. & 20 & 8 & 18 & 5 & 11 & 5 \\
\hline $40 \mathrm{~min}$. & 83 & 37 & 58 & 23 & 50 & 18 \\
\hline $60 \mathrm{~min}$. & 110 & 49 & 70 & 35 & 43 & 29 \\
\hline $120 \mathrm{~min}$. & 115 & 43 & 70 & 30 & 39 & 30 \\
\hline $240 \mathrm{~min}$. & 90 & 33 & 85 & 39 & 40 & 32 \\
\hline
\end{tabular}

* Concentration of cations in the medium $\mu \mathrm{g} / \mathrm{ml}: \mathrm{Na}^{+} 210, \mathrm{~K}^{+} 70$

$B$. subtilis cells were grown under the experimental conditions given in the text. Five ml samples of treated and non-treated control cultures were withdrawn at the preindicated incubation periods, washed with bidistilled water and the concentration of $\mathrm{Na}^{+}$and $\mathrm{K}^{+}$ions were determined using the Perkin Elmer atomic absorption spectrophotometer type 403 according to manufacturer's instructions (March 1971). 
Fig. 4. Effect of kuwaitimycin on B. subtilis protoplasts

Washed cells of $B$. subtilis were suspended in a phosphate buffer ( $\mathrm{pH} 7.2$ ) containing $0.5 \mathrm{M}$ sucrose and $100 \mu \mathrm{g} / \mathrm{ml}$ of lysozyme. The suspension was incubated for 90 minutes at $30^{\circ} \mathrm{C}$. The formation of protoplasts was confirmed microscopically. The effect of kuwaitimycin was determined as follows: (ca. $2 \times 10^{5} \mathrm{cell} / \mathrm{ml}$ ), and $0.3 \mathrm{ml}$ of solution containing the antibiotic were added to give a final volume of $3 \mathrm{ml}$. The mixture was incubated at $37^{\circ} \mathrm{C}$ and the turbidity at $660 \mathrm{~nm}$ was measured at the preindicated incubation periods.

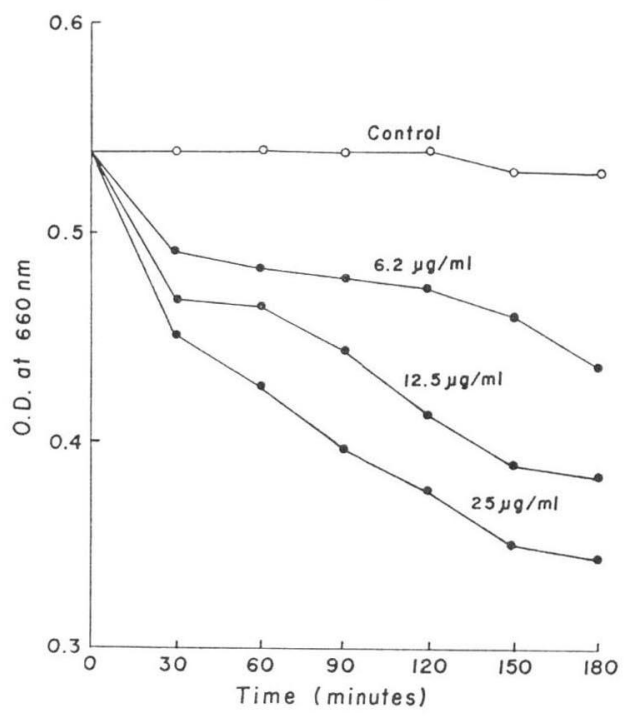
$2.7 \mathrm{ml}$ of a suspension of $B$. subtilis protoplasts

mycin which can be attributed to changes in lipid contents of the bacterial cell membrane and consequent alteration of its permeability. Similar conclusions were reported in cases of bacitracin $^{10)}$ and polymyxins ${ }^{11)}$.

Kuwaitimycin caused bursting of B. subtilis protoplasts in hypertonic solutions probably due to changes in conformation and rigidity of cell membrane that can be attributed to variation in lipid composition (Fig. 4).

\section{References}

1) Shimi, I. R.; A. Dewedar \& S. Shoukry: Kuwaitimycin, a new antibiotic. J. Antibiotics 26: $593 \sim 601,1973$

2) SHImI, I. R.: On the mode of action of kuwaitimycin. J. Antibiotics 27: 316 320, 1974

3) Shimi, I. R. \& S. Shoukry: On the mode of action of ASK-753 on Bacillus subtilis. J. Antibiotics 29: 303 308, 1976

4) Bligh, E. G. \& W. J. Dyer: A rapid method of total lipid extraction and purification. Canad. J. Biochem. Physiol. 37: $911 \sim 917,1959$

5) KANEDA, T.: Biosynthesis of branched chain fatty acids. VI. Factors affecting relative abundance of fatty acids produced by $B$. subtilis. Canad. J. Microbiol. 2: $501 \sim 514,1966$

6) William, D. N. \& B. E. Trapp: Effect of phenethyl alcohol on phospholipid metabolism in E. coli. J. Bact. 109: 162 168, 1972

7) Shimi, I. R. \& S. Shoukry: The mode of action of polyketoacidomycin on B. subtilis. J. Antibiotics 27: 859 865, 1974

8) Kusano, T.; K. Izaki \& H. Takahashi: Degradation of phospholipids in Pseudomonas aeruginosa by polymyxins B. J. Antibiotics 28: 689 695, 1975

9) Ringrase, P. S. \& J. E. Higgins: The inter-relationship of tetracycline resistance, deconyl-N-acetyl cysteamine and membrane fatty acid composition in Escherichia coli. J. Antibiotics 27: 833 837, 1974

10) Hancock, R. \& P. C. Fitz-James: Some differences in the action of penicillin, bacitracin and vancomycin on Bacillus megaterium. J. Bact. 87: 1044 1050, 1964

11) Newton, B. A.: The properties and mode of action of polymyxins. Bact. Rev. 20: 14 27, 1956 